\title{
CLAVES PARA LA COMPRENSIÓN Y EL APRENDIZAJE DEL CONCEPTO DE COHERENCIA DISCURSIVA
}

\author{
Pilar Alonso Rodríguez \\ Universidad de Salamanca
}

\begin{abstract}
RESUMEN: El artículo aborda el concepto de coherencia en el discurso, reconoce su importancia en los procesos de producción y comprensión lingüística y las dificultades que se plantean a la hora de explicarlo cuando se trata del aprendizaje de una lengua extranjera (en este caso la lengua inglesa), ya que el estudiante puede no estar capacitado para enfrentarse al mismo de forma intuitiva. Para ello se proporcionan siete claves basadas en conceptos de la semántica del discurso cuyo desarrollo facilita la enseñanza de la noción de coherencia y su aplicación.
\end{abstract}

ABSTRACT: This article tackles the concept of discourse coherence, and its importance in the processes of language production and comprehension. It deals with the problems which may occur when the concept has to be explained to students of English as a foreign language, who may not be able to approach it intuitively. It proposes using seven key notions based on semantic discourse analysis to show how coherence is achieved and developed in English. The notions are explained and then applied to a real text in English.

\section{Primera Parte: Aspectos Teóricos}

El concepto de coherencia atañe al contenido y la organización de la información discursiva, así como a la aceptación de la misma por parte del receptor. Es junto al concepto de cohesión fundamental a la hora de elaborar e interpretar el discurso y el conocimiento de sus presupuestos resulta muy útil en el aprendizaje de una segunda lengua o de una lengua extranjera, porque facilita tanto la creación como la comprensión de textos.

La coherencia es, sin embargo, un concepto difícil de concretar, debido principalmente a que sus constituyentes son de índole diversa: semánticos, cognitivos y pragmáticos. Ante la dificultad, algunos lingüistas tienden a definirlo haciendo uso de nociones intuitivas: Por ejemplo, van Dijk dice que "intuitivamente, la coherencia es una propiedad semántica de los discursos" ("intuitively, coherence is a semantic property of discourses" $(1977,93)$ ), mientras que Brown y Yule, adoptando un enfoque más pragmático, definen el término como "algo que aquellos que usan el lenguaje asumen de manera natural" (" "coherence' is something language users naturally assume" 
$(1983,66))$. Otras aproximaciones supeditan la coherencia discursiva a la búsqueda de relevancia por parte del receptor, haciendo nuevamente responsables a los participantes en la comunicación de los criterios a seguir (Sperber \& Wilson 1986,1995; Blakemore 1992). Aunque, en el mejor de los casos, las posiciones pueden combinarse hasta alcanzar una visión global del fenómeno (Bernárdez 1995), la solución más general consiste en desarrollar el concepto de coherencia, renunciando a definirlo. El resultado suele ser una descripción con frecuencia demasiado compleja y teórica donde la necesidad de profundizar en determinados aspectos obliga a descuidar otros.

La aplicación de cualquiera de estos procedimientos en el marco de la enseñanza de una lengua extranjera es harto dificultosa. Primero, porque no está garantizado que el alumno no nativo posea la intuición lingüística necesaria para inferir por sí solo si un texto es coherente o no. Segundo, porque los tratados de lingüística teórica desbordan sus intereses. La labor de síntesis y de selección se convierte así en una prioridad a la hora de acercar la noción de coherencia no al especialista que puede y debe conocerla en su complejidad, sino al estudiante para concienciarle de su importancia en los terrenos del uso (producción y recepción de textos) y del análisis. Las notas que voy a exponer a continuación proporcionan una serie de claves que permiten abordar la comprensión y el aprendizaje de la coherencia de manera sistemática y manejable mediante la exploración y la identificación en los textos de los conceptos teóricos en los que se centran.

\section{Semántica del discurso: cohesión y coherencia.}

La primera clave que puede ofrecerse al estudiante es la identificación de coherencia como concepto complementario al de cohesión. Ambos son propiedades semánticas del discurso, pero dado que los recursos de cohesión son de carácter formal y pueden distinguirse fácilmente mediante la realización de ejercicios prácticos, el proceso de aprendizaje de la coherencia se facilita en cierta medida si en primer lugar se explica la cohesión y se practica su análisis (Halliday \& Hasan 1976, Schiffrin 1987). Después se tomará como base hipotética de la coherencia discursiva todo aquello que sostiene el entramado significativo del texto y no es cohesión propiamente dicha. Llegado este punto es necesario matizar que en la realidad discursiva nada existe de manera aislada, muy al contrario todos los componentes del texto son interactivos y mutuamente relevantes, con lo que puede decirse que cohesión no es coherencia pero ambos conceptos existen relacionados y se complementan.

\section{Coherencia local y coherencia global.}

La segunda clave que proponemos gira en torno a los conceptos de coherencia local y coherencia global, o lo que es lo mismo, al mayor o menor alcance de las rela- 
ciones de coherencia. Las relaciones de coherencia pueden darse entre proposiciones que se hallan contiguas o próximas entre sí o entre proposiciones o secuencias textuales cuya distribución en el texto es más alejada o dispersa. Las primeras afectan a lo que van Dijk denomina "coherencia local” y su contribución a la obtención de un significado total del texto está en relación directa a la progresión lineal del mismo, es decir, ayudan a la construcción de la coherencia textual en un proceso que podría describirse como "paso a paso". Las segundas constituyen lo que van Dijk llama "coherencia global" y sirven para establecer redes de significado que afectan al contenido general del texto y al conjunto de su estructura semántica o macroestructura. Van Dijk (1977) relaciona estas conexiones semánticas de largo alcance con la manera en que se presenta, se organiza, y se distribuye la información. Por la importancia que tienen estas operaciones en la construcción de la coherencia textual, las tres claves siguientes girarán en torno a esta cuestión.

No obstante, antes de avanzar en este sentido, hay que recordar nuevamente que la interacción entre ambos tipos de relaciones está siempre vigente. Así las relaciones de coherencia local pueden no tener mayor relevancia que la concerniente a su cotexto inmediato, pero por lo general inciden sobre el conjunto del texto hasta convertirse en una fuente de coherencia global, sea por sí mismas o en combinación con otros recursos propios de la cohesión. En cualquier caso hay que recalcar que no es posible llegar a una descripción sistemática de la coherencia global sin un conocimiento previo de la coherencia local.

\section{Las relaciones de significado y la organización jerárquica de la información en el discurso.}

La tercera clave busca describir cómo se obtiene la coherencia global partiendo de las relaciones locales de significado entre las distintas proposiciones y de la presentación jerarquizada de la información. Teniendo en cuenta el carácter necesariamente lineal de la producción lingüística, la información se distribuye en proposiciones que sostienen entre sí relaciones semánticas de índole diversa y cuya mayor o menor relevancia está determinada por la naturaleza de su contenido y/o por su colocación en el discurso.

En primer lugar hemos de considerar las relaciones semánticas que vienen dadas por la manera en que los hablantes perciben el entorno (van Dijk 1977). Así es frecuente que en el texto, o en el discurso, la información se organice, por ejemplo, de lo general a lo particular, de lo conocido a lo desconocido, de lo perceptible a lo imperceptible, del todo a la partes, de lo anterior a lo posterior, del pasado al presente, de la causa al efecto, o a la inversa en cada uno de los casos. Esto no afecta exclusivamente al significado conceptual de las diversas proposiciones y a la correlación entre las mismas. También juega un papel importante la dimensión semántica de los elementos 
morfológicos y sintácticos, como son sustantivaciones, modulación verbal, uso de los tiempos verbales, selección de funciones dentro de la oración (agente o receptor de la acción) etc. De ahí la importancia de que los alumnos tengan un conocimiento previo del funcionamiento de las unidades lingüísticas mínimas.

Del mismo modo resulta de gran utilidad para el análisis de la coherencia local el principio de "repetición de argumento" desarrollado por van Dijk y Kintsch, según el cual "dos proposiciones están relacionadas si comparten el mismo argumento" ("two propositions are related if they share a common argument" (1983, 43)). El principio sostiene que no todas las proposiciones del discurso están situadas a un mismo nivel, sino que se presentan jerarquizadas. Se considera proposición principal aquella que sirve para introducir un argumento dado y subordinadas a ésta hallaríamos todas las proposiciones que anticipan, retoman, explican, puntualizan, modifican o expanden este argumento. En el tercer nivel se encontrarían a su vez aquellas otras proposiciones que compartirían su argumento con las del segundo nivel y así sucesivamente.

Van Dijk establece que las relaciones de coherencia que se dan entre las proposiciones del discurso pueden ser explícitas o implícitas. Las relaciones explícitas deben entenderse como marcadas en el texto, ya sea mediante elementos interpretados inicialmente como cohesivos (conectores conjuntivos, referencia, reiteración léxica, etc.), o mediante operaciones organizativas o estructurales relativas al orden que el productor establece a la hora de introducir y desarrollar la información. En cuanto a las relaciones implícitas (o "missing links" [nexos ausentes] (van Dijk 1977, 94-5)) suelen ser de contenido semántico similar al descrito para las explícitas, con la diferencia de que las implícitas no están marcadas en el texto y han de ser inferidas por el receptor. Se trata pues de elevar al plano de lo consciente la asimilación intuitiva de las mismas.

Para identificar todas las relaciones que se encuentran activas en un texto determinado es necesario analizar su microestructura. Este análisis debe ser descriptivo como proponen Brown y Yule $(1983,112-15)$, en lugar de lógico según la práctica habitual de van Dijk. Esto hace que la labor sea más asequible y más útil para el estudiante.

\section{El tema o punto de partida.}

La cuarta clave que proponemos investigar es la noción de tema. Esta noción, junto con las de "tópico" y "comentario" que trataremos a continuación, tiene su origen en el análisis semántico de la oración, pero puede trasladarse, con algunas variaciones, al discurso donde resulta de gran utilidad. Hay que mostrar cómo el punto de partida elegido para la presentación de la información es relevante porque modula y enfoca el texto. A grandes rasgos puede decirse que el tema del discurso lo establece aquella proposición que ocupa la posición temática, es decir, la proposición que se 
presenta en primer lugar dentro de la linealidad de la unidad discursiva, teniendo en cuenta que también aquí actúa la jerarquía.

Pero debemos hacer constar que un discurso, si es de cierta extensión, no suele ser un bloque compacto. Por lo general hay subdivisiones en forma de párrafos, secciones, capítulos, partes etc. Cada uno de ellos presentará un elemento tematizado y su importancia en el conjunto de la información textual vendrá dada por la posición que ese bloque ostente con relación a la totalidad del texto (por ejemplo, un párrafo es jerárquicamente inferior a una sección, que a su vez es inferior a un capítulo, siendo éste inferior a una parte, y así sucesivamente). La repetición en la tematización de un mismo elemento lo convierte en prominente para la información textual.

\section{El tópico del discurso}

Como quinta clave proponemos la noción de tópico discursivo de gran importancia para establecer la coherencia de un texto. Brown y Yule califican aquello de lo que habla el texto como "tópico del hablante" de lo que se deduce que corresponde a éste marcar explícitamente tanto el mantenimiento de un mismo tópico como la posible introducción de otro nuevo $(1983,71)$.

Generalmente el tópico de un discurso suele inferirse de manera intuitiva, pero existe una operación semántica, de ejecución prácticamente matemática, que permite averiguar con suficiente precisión cuál es el tópico discursivo (Alonso, 1995). Para ello se contabilizan todos los elementos que tienen función de tópico en las distintas proposiciones del discurso, es decir todos aquellos que operan como sujeto en el orden sintáctico. El elemento que desempeña más frecuentemente la función de tópico oracional es el principal candidato al papel de tópico del discurso. Su candidatura se incrementa si además ocupa con suficiente asiduidad el puesto de tema, lo que no es raro.

Debo matizar dos cosas: primero, que admitimos como identidad en el tópico no sólo las repeticiones léxicas, sino también las reiteraciones en el modo en que las conciben Halliday y Hasan (sinónimos, superordinados, palabras generales, relaciones referenciales, etc.) y, segundo, que también en este orden ha de tenerse en cuenta la jerarquía. De este modo, el tópico de una oración principal es de entrada más relevante que el de una subordinada, la posición temática de un bloque discursivo es más prominente que la de una oración en posición intermedia, etc.

Como complemento al concepto de tópico del discurso hay que añadir el de su correlato "comentario" o "comento". Hemos de mostrar como, en el discurso, la suma de todos los comentarios oracionales recoge aquello que se predica o dice del tópico proporcionándole su contenido. 


\section{El concepto de mundo textual.}

La sexta clave se inspira en el concepto de mundo textual (de Beaugrande 1980, de Beaugrande \& Dressler 1981, Bernárdez 1995). Según de Beaugrande, el mundo textual es el correlato cognitivo del entramado de conceptos y relaciones activado por las expresiones de un texto ("a textual world is the cognitive correlate in the mind of a text user for the configuration of concepts and relations activated by the expressions of a text $(1980,77))$. Así pues, la utilización de todo texto conlleva la creación de un mundo textual en la mente de todos los participantes en la comunicación. Para establecer la existencia o no de coherencia dentro del mundo textual es importante precisar el carácter de las relaciones que actúan junto a los conceptos en la construcción del significado global del texto. Ya hemos mencionado algunas de las relaciones de significado vigentes en el plano local. Vamos a completarlas ahora con otras, también descritas por van Dijk (1977), que suelen ser de mayor alcance. Me estoy refiriendo a las relaciones de identidad y a las relaciones de diferencia que se dan entre las proposiciones del discurso.

Las relaciones de identidad y diferencia no se refieren a la mayor o menor dependencia de significado entre proposiciones contiguas o próximas. Las relaciones de identidad pueden afectar a las entidades, a las propiedades y/o a las relaciones presentes en todo el discurso, de ahí su alcance global. Por ejemplo, las diferentes proposiciones pueden todas ellas expresar algo sobre una misma entidad, puede decirse de dos o más entidades que comparten una cualidad, o se puede establecer relaciones de similitud entre dos o más entidades. Igualmente, puede darse una relación de identidad entre proposiciones si comparten el mismo contexto sea en términos de situación, de tiempo, o de mundo posible.

Las relaciones de diferencia y cambio son de carácter semejante a las de identidad, pero, como su propio nombre indica, no establecen la similitud sino la diferencia que existe entre las distintas entidades en función de un desarrollo que, por otra parte, es natural a todo texto o discurso. Como señala van Dijk, el discurso no dice siempre lo mismo de los mismos individuos, más bien al contrario. Sin embargo, para que el discurso sea coherente, hay que tener en cuenta que las relaciones de diferencia y cambio deben ser homogéneas, o lo que es lo mismo, mutuamente compatibles y adecuadas a la situación discursiva.

Dependiendo de las propiedades que el productor haya decidido asignar a los componentes textuales, el mundo textual con su red de conceptos y relaciones podrá ser más o menos coincidente con el mundo real. Pero en cualquier caso los conceptos activados por el texto no permanecen aislados en la mente del productor o del receptor. Es necesario señalar que el mundo textual también establece relaciones de significado fuera de su entramado verbal, alcanzando así una dimensión cognitiva. La información contenida en el texto se relaciona de manera interactiva con las estructuras de conocimiento ya existentes en la mente de los participantes y con su contenido, sea 
éste de tipo enciclopédico o experimental. Así la relación da lugar a una serie de operaciones dinámicas que pueden modificar y enriquecer el texto base. Su interacción con el conocimiento preexistente por medio de estrategias de connotación o de inferencia permite, por ejemplo, actualizar el conocimiento, ampliarlo e incluso introducir en él cambios significativos.

\section{Los principios de interpretacion local y de analogía}

La septima clave que proponemos vamos a obtenerla de los principios de interpretación local y de analogía desarrollados por Brown y Yule que rigen según estos autores el comportamiento de los receptores. Siguiendo lo que ellos denominan "principio de interpretación local", los receptores siempre activan el contexto mínimo necesario para la comprensión y la interpretación del discurso ("the principle of local interpretation... instructs the hearer not to construct a context any larger than s/he needs to arrive at an interpretation"(1983, 59)). Del mismo modo, siguiendo el principio de analogía, los receptores siempre interpretan el discurso guiados por su experiencia previa en situaciones discursivas similares y por analogía con textos similares previos ("the principle of analogy instructs the hearer to interpret discourse in the light of past experience of similar discourse, by analogy with previous similar texts" (65)).

Los dos principios influyen directamente en la creación y el mantenimiento de la coherencia textual, incidiendo esta vez en su dimensión pragmática. Como Brown y Yule dicen, observando ambos principios, los oyentes o lectores tienden a interpretar de manera natural las secuencias proposicionales como relativas a un mismo tópico y a un mismo contexto y a mantenerse dentro de los límites del mismo $(1983,65)$. Esto significa que el receptor asume una postura cooperativa dentro de la cadena comunicativa en lo que a la coherencia discursiva se refiere, como algo que espera y a cuyo establecimiento contribuye (Grice 1975).

\section{Coherencia y creatividad}

Hasta ahora hemos descrito la obtención y el mantenimiento de la coherencia discursiva en términos que podríamos definir como "normales" atendiendo a lo que conocemos como la forma más lógica de organizar el discurso. Sin embargo, es frecuente en determinados tipos de discurso (por ejemplo, el discurso literario, el periodístico, el publicitario, etc.) que el orden lógico se altere para producir un efecto determinado en el receptor. En estos tipos de discurso, la coherencia suele obtenerse haciendo intencionadamente un uso desviado o creativo de las normas convencionales (por ejemplo, ocultando la información esencial hasta el último momento para mantener alerta la atención del receptor). Cuando se enseña el concepto de coherencia es 
preciso indicar que, en la producción textual propia, cualquier desviación de la norma debe utilizarse para añadir significación al texto y no de manera gratuita porque puede interferir con la asunción de coherencia. Del mismo modo debe señalarse que en la interpretación o en el análisis discursivo todas las desviaciones deben valorarse como significativas.

\section{Segunda Parte: Aplicación Práctica}

Presentamos ahora un texto auténtico y completo que analizaremos según las claves expuestas anteriormente. Para facilitar el procedimento de análisis, todas las oraciones del texto han sido marcadas al final con un número entre paréntesis que las identifica.

\section{AFTER ELEVEN YEARS WOODY AND MIA ARE THROWING IN THE TOWEL}

They made an odd couple, to be sure: tenacious live-aparts who used to wave towels at each other from their respective homes on opposite sides of Central Park (1). Now, after 11 years as serious soul mates, Woody Allen and Mia Farrow are instead brandishing court papers (2). Reportedly calling her an unfit mother, the director has sued the star of his professional and private lives for custody of three of her eleven children: Woody's biological son Satchel, 4 1/2, and two kids they adopted - daughter Dylan, 7, and son Moses, 14, who has cerebral palsy (3).

There had been occasional blips of disharmony on the screen of their relationship (4). Woody had worried in 1985 when Mia decided to adopt an eighth child — and a few months ago, he told syndicated columnist Liz Smith that he opposed her intent to adopt two more both with disabilities (5). But what finally brought the shadows and fog to their Manhattan interiors? (6) Was it one too many jars of strained bananas? (7) Another woman? (8) The prospect of September? (9) Did he threaten to take the money and run? (10) Or was she the one guilty of crimes and misdemeanors? (11) Whatever transformed their midsummer night's sex comedy into stardust memories, Woody and Mia now clearly won't end up like the couples in their next movie, opening this fall: "Husbands and wives"(12).

Newsweek, August 24, 1992 (pág. 31) ${ }^{1}$

\section{Semántica del discurso: cohesión y coherencia.}

La primera clave proponía el conocimiento y puesta en práctica de los mecanismos de cohesión para identificar por exclusión los aspectos fundamentales de la cohe-

1. Agradecemos a la revista Newsweek el que nos haya permitido reproducir íntegramente este texto. 
rencia. Puesto que la cohesión no es el principal objetivo de este trabajo y la identificación de sus componentes formales no ofrece la menor dificultad, no haremos aquí un análisis exhaustivo. Nos limitaremos a ofrecer algunos ejemplos de los diferentes recursos que se encuentran en el texto (Halliday \& Hasan, 1976; Halliday, 1985).

\section{Referencia:}

a) anafórica : they $(1,3)$ personal a Woody and Mia, en el título y en (2); her (3) personal a Mia Farrow en el título y $(2) ;$ he $(5,10)$ personal a Woody Allen en (2); she (11) personal a Mia Farrow en (2); instead (2) comparativa con referencia a la proposición contenida en la oración anterior; two more (5) comparativa con referencia a la proposición contenida en la clausula anterior; another woman (8) comparativa con referencia a Mia Farrow en el título y (2); the one (11) comparativa con referencia a Mia Farrow y por oposición a Woody Allen.

b) catafórica: they (1) a (2) si no se tiene en cuenta el título.

c) exofórica : this fall (12) al contexto externo.

2. Sustitución : it (7) sustituye a la proposición anterior;

3. Elipsis : [they were] tenacious live-aparts... (1); [was it] the prospect of... (9);

4. Conjunción : Now $(2,12) ;$ Or $(11)$

\section{Cohesión léxica}

$\left.\mathrm{a}_{1}\right)$ repetición: Woody $[$ Allen $](2,5,12) ;$ Mia $[$ Farrow $](2,5,12)$

$\mathrm{a}_{2}$ ) reiteración: towels (1); the director (3), the star (3) woman (8) a Woody Allen y Mia Farrow respectivamente mediante superordinados genéricos.

b) colocación : mother, children, kids, son, daughter, adopted (3), husbands and wives (12) con couple, homes (1), soul-mates (2); screen (4) con director, star (3); has sued (3), custody (3) con court papers (2); Manhattan (6) con Central Park (1).

\section{Coherencia local y coherencia global.}

Los rasgos que contribuyen en el texto a la obtención de la coherencia local y de la coherencia global serán analizados en los apartados siguientes: el apartado 3 se centrará más en las relaciones de coherencia local y los restantes tratarán distintos aspectos de la coherencia global.

Puede hacerse notar ahora la interdependencia de significado que se da a todos los niveles textuales: la globalidad del texto necesita para su comprensión de la lectura de todas las proposiciones que lo forman; del mismo modo, para la comprensión 
individual de cada una de las proposiciones también es necesaria la información completa que se obtiene de la totalidad del discurso. Por ejemplo, la primera proposición (1) no se entendería en absoluto si se presentase de manera aislada. La segunda (2) se comprendería mejor porque da los referentes, pero la información seguiría siendo incompleta. Ambas proposiciones obtienen todo su significado dentro del marco global del discurso, lo mismo puede decirse de todas las demás proposiciones. A todo ello hay que añadir el conocimiento del mundo que se presupone al receptor.

\section{Las relaciones de significado y la organización jerárquica de la información en el discurso.}

Como ejes de la coherencia local hemos considerado la presentación jerarquizada de la información y las relaciones semánticas que se establecen entre las proposiciones, teniendo en cuenta la necesaria linealidad del discurso. Como se ha dicho, este último factor suele actuar como condicionante en la organización de la información aconsejando — según un orden considerado convencionalmente como lógico- que se vaya de lo general a lo particular, del pasado al presente, de lo conocido a lo desconocido, de lo perceptible a lo imperceptible, del todo a las partes, de la causa al efecto, etc.

En el texto que analizamos se cumplen estos requisitos:

\section{Relación general - particular :}

Los aspectos relativos al estado de las cosas (tiempo, lugar, situación, etc.) se introducen en las primeras proposiciones (1) y (2). En las restantes se proporcionan los detalles particulares.

\section{Relación pasado - presente :}

En el primer párrafo se va del pasado (1) al presente $(2,3)$. En el segundo párrafo también se va del pasado $(4,5)$ al presente (6-12).

3. Relación conocido - desconocido / perceptible - imperceptible :

Las tres primeras partes del texto relatan los elementos conocidos en la relación y consecuentemente perceptibles (1-5), el resto hasta la última proposición especula con las causas desconocidas (6-11).

\section{Relación todo-partes:}

Las dos primeras proposiciones $(1,2)$ en el primer párrafo consideran a la pareja en conjunto, la tercera lo hace por separado. Lo mismo ocurre en el segundo párrafo: (4) en conjunto, (5-11) por separado; la última proposición (12) retoma el conjunto, para presentar la consecuencia. 
5. Relación causa - efecto :

La totalidad de las proposiciones del texto (1-11) con relación a la última proposición (12).

También se da la relación local entre las proposiciones: de contraste (1-2) y explicación (3 hasta 11) para desembocar todas ellas en la aseveración que sirve de conclusión.

Un ejercicio útil, en el que no vamos a entrar, sería especificar hasta qué punto estas relaciones se apoyan en nexos explícitos o se realizan de manera implícita.

\section{El tema o punto de partida.}

La estructura temática del texto es consistente con lo dicho hasta ahora en el ámbito de las relaciones semánticas tanto en lo relativo a su microestructura (elementos tematizados de las sucesivas proposiciones) como a su macroestructura (primer elemento tematizado del cuerpo textual).

Los temas de las diferentes proposiciones, algunos de ellos coincidentes con el tópico, son los siguientes:

They (1), Now (2), Reportedly...unfit mother (3), There (4), Woody (5), But (6), Was (7) Another woman? (8), The prospect of September? (9), Did (10) Or (11), Whatever.. memories (12).

$\mathrm{Su}$ análisis revela que el punto de partida de la globalidad del discurso (1) es la pareja Woody-Mia (They) a la que se presenta como conocida (uso del referente personal y función de tópico). Los elementos tematizados de las restantes proposiciones hacen avanzar el desarrollo semántico del discurso principlamente en dos direcciones: la temporal y la explicativa (o búsqueda de una explicación). En (2) se toma como elemento temático el referente tiempo (Now) por oposición a la proposición precedente (tiempo verbal pasado); $(3,4,5)$ presentan elementos tematizados diversos de significación local que actúan en función del carácter explicativo de las proposiciones que introducen; (6) marca un cambio por contraste en el tono discursivo mediante la tematización del nexo inter-oracional adversativo (But). Así se pasa de la explicación aseverativa a la especulativa o hipotética como demuestran los sucesivos temas de todas las proposiciones restantes (7-12), todos ellos de índole interrogativa.

\section{El tópico del discurso}

En lo referente al tópico, hemos de seguir un procedimiento semejante al utilizado para identificar la estructura temática. Primero deben contabilizarse los tópicos proposicionales y a continuación se debe estudiar su frecuencia para deducir de la misma la naturaleza del tópico discursivo. Aunque podría ser interesante considerar 
también el tópico de las subordinadas para dilucidar cuestiones relativas a la organización jerarquizada de la información, aquí nos vamos a limitar a los tópicos de la unidad proposicional, es decir, a los que ejercen la función sintáctica de sujeto en las oraciones principales.

Un sencillo análisis arroja los siguientes datos:

1.Woody Allen y Mia Farrow son conjuntamente el tópico de 3 proposiciones (1, $2,12)$ - significativamente, las dos primeras y la última-.

2.Por separado, Woody es tópico en 3 proposiciones $(3,5,10)$ y Mia lo es en 1 proposición (11)

3. Todas las restantes proposiciones tienen tópicos indefinidos : there (4), what (6), it (7 y elíptico en 8, 9). Debe señalarse además que los tópicos en 6-9 son elementos interrogativos (6) o forman parte de una estructura interrogativa (7, $8,9)$.

Podemos inferir de este análisis que el tópico global del texto es: "Woody Allen y Mia Farrow y la causa desconocida [de su separación]". La separación y los datos que sobre ella se aportan son el comentario o nueva información que se ofrece a los lectores. Es interesante notar igualmente que la presencia de Woody Allen es ligeramente superior en el texto (3 veces tópico) a la de Mia Farrow (1 vez tópico) por lo que ello pueda tener de significativo a la hora de establecer el punto de vista predominante.

\section{El concepto de mundo textual.}

Una vez activado en la mente del receptor un determinado mundo textual (Woody Allen/Mia Farrow-> relación entre ambos) basado en la asunción de un determinado conocimiento del mundo, la coherencia dentro de ese mundo textual se obtiene efectivamente mediante relaciones de identidad y diferencia.

Las relaciones de identidad vienen dadas por las entidades a las que se refiere la información contenida en todas las proposiciones del texto (Woody / Mia). Las relaciones de diferencia se estructuran en torno a los componentes situacionales: cambios en el tiempo. Así, en el primer párrafo, se aborda el pasado (1), el presente (2). En el segundo párrafo, pasado $(4,5)$, pasado-presente (6-11), presente-futuro (12). Las relaciones de identidad confieren coherencia al conjunto textual, las de diferencia permiten el avance y desarrollo de la información.

\section{Los principios de interpretacion local y de analogía}

Por último, los principios de interpretación local y analogía rigen la respuesta del receptor y su cooperación en el proceso comunicativo. La inclusión del texto en una 
sección determinada de la revista en la que aparece (sección "Newsmakers" de Newsweek ) hace que su interpretación y valoración se produzca según unas claves concretas sin exigir el rigor y la seriedad que se espera de las restantes secciones de la revista. De nuevo interviene aquí de forma activa el componente cognitivo-pragmático, basado en la experiencia previa y el conocimiento del mundo.

\section{Conclusión}

A modo de conclusión podemos decir que la exploración consecutiva de las claves aquí descritas en un texto cualquiera y la valoración global de las mismas permite al estudiante adquirir una idea clara de los mecanismos de coherencia activos en la producción textual, así como de los recursos de los que dispone como hablante para dotar de coherencia a sus propios textos. La teoría debe completarse siempre con ejercicios prácticos de análisis de textos auténticos íntegros. Es importante insistir en la fuerte trabazón semántico-discursiva que los componentes de cohesión y coherencia otorgan a la unidad textual y cómo esto se pone de manifiesto mediante el análisis.

\section{Bibliografía}

Alonso, P. (1995). "Summary Writing and Summary Evaluation: A Method Based on Semantic Discourse Analysis". Estudios Ingleses de la Universidad Complutense, Número 3, págs.151-171.

Beaugrande, R. de (1980). Text, Discourse, and Process. Norwood, N.J.: Ablex.

BeAugrande, R. de \& Dressler, W. (1981). Introduction to Text Linguistics. London: Longman.

Bernardez, E. (1995). Teoría y Epistemología del Texto. Madrid: Cátedra.

BLAKEMORE, D. (1992). Understanding Utterances. Oxford: Blackwell.

Brown, G. \& Yule, G. (1983). Discourse Analysis. Cambridge: Cambridge University Press.

Ehrlich, S. (1990). Point of View. London and New York: Routledge.

GRICE, H.P. (1975). Logic and Conversation. In P. Cole and J. Morgan (Eds.). Syntax and Semantics, vol. 3: Speech Acts. New York: Academic Press.

Halliday, M.A.K. and HasAn, R. (1976). Cohesion in English . London: Longman. SAEED, J.I. (1997). Semantics. Oxford: Blackwell.

Schiffrin, D. (1987). Discourse Markers. Cambridge: Cambridge University Press. SPERBER, D. \& Wilson, D. (1986,1995). Relevance. Oxford: Blackwell.

van DiJK, T. A., (1977). Text and Context. London: Longman.

VAN DiJK, T. A. (1980). Macrostructures . Hillsdale, N.J.: Lawrence Erlbaum.

VAN Disk, T. A. (Ed.) (1997). Discourse as Structure and Process. London.: Sage. 
VAN DiJK, T. A. \& KInTCH, W. (1982). Strategies of Discourse Comprehension. New York: Academic Press.

\section{Texto Analizado}

"After eleven years Woody and Mia are throwing in the towel." From Newsweek, 08/24/92. (C) 1992, Newsweek, Inc. All rights reserved. Reprinted by permission. 